Baliatsas, C., Kamp, I. van, Poll, R. van, Yzermans, J. Health effects from low-frequency noise and infrasound in the general population: is it time to listen? A systematic review of

\begin{tabular}{|c|c|}
\hline $\begin{array}{l}\text { Postprint } \\
\text { Version }\end{array}$ & 1.0 \\
\hline Journal website & $\begin{array}{l}\text { http://www.sciencedirect.com/science/article/pii/S0048969716304338?via\%3Dih } \\
\underline{\mathrm{ub}}\end{array}$ \\
\hline Pubmed link & https://www.ncbi.nlm.nih.gov/pubmed/?term=26994804 \\
\hline DOI & 10.1016/j.scitotenv.2016.03.065 \\
\hline
\end{tabular}

This is a NIVEL certified Post Print, more info at http://www.nivel.eu

\title{
Health effects from low-frequency noise and infrasound in the general population: Is it time to listen? A systematic review of observational studies
}

\section{CHRISTOS BALIATSAS ${ }^{A}$ IRENE VAN KAMP ${ }^{\mathrm{B}}$ RIC VAN POLL $^{\mathrm{B}} \mathrm{JORIS}_{\text {YZERMANS }}{ }^{\mathrm{A}}$}

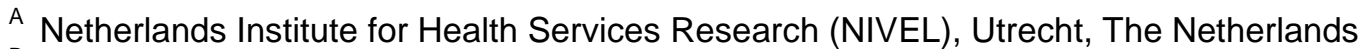

B National Institute for Public Health and the Environment (RIVM), Bilthoven, The Netherlands

\section{Highlights}

A part of the population reports high annoyance attributed to LFN sources.

LFN is associated with self-reported outcomes, mainly neurological.

Current evidence is very limited, especially regarding chronic conditions.

More epidemiological research on LFN and health effects is needed.

\begin{abstract}
A systematic review of observational studies was conducted to assess the association between everyday life low-frequency noise (LFN) components, including infrasound and health effects in the general population. Literature databases Pubmed, Embase and PsycInfo and additional bibliographic sources such as reference sections of key publications and journal databases were searched for peer-reviewed studies published from 2000 to 2015. Seven studies met the inclusion criteria. Most of them examined subjective annoyance as primary outcome. The adequacy of provided information in the included papers and methodological quality of studies was also addressed. Moreover, studies were screened for meta-analysis eligibility. Some associations were observed between exposure to LFN and annoyance, sleep-related problems, concentration difficulties and headache in the adult population living in the vicinity of a range of LFN sources. However, evidence, especially in relation to chronic medical conditions, was very limited. The estimated pooled prevalence of high
\end{abstract}


Baliatsas, C., Kamp, I. van, Poll, R. van, Yzermans, J. Health effects from low-frequency noise and infrasound in the general population: is it time to listen? A systematic review of observational studies. Science of the Total Environment: 2016, 557, 163-169

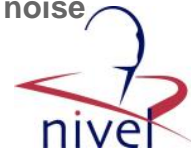

subjective annoyance attributed to LFN was about 10\%. Epidemiological research on LFN and health effects is scarce and suffers from methodological shortcomings. Low frequency noise in the everyday environment constitutes an issue that requires more research attention, particularly for people living in the vicinity of relevant sources.

\section{GRAPHICAL ABSTRACT}

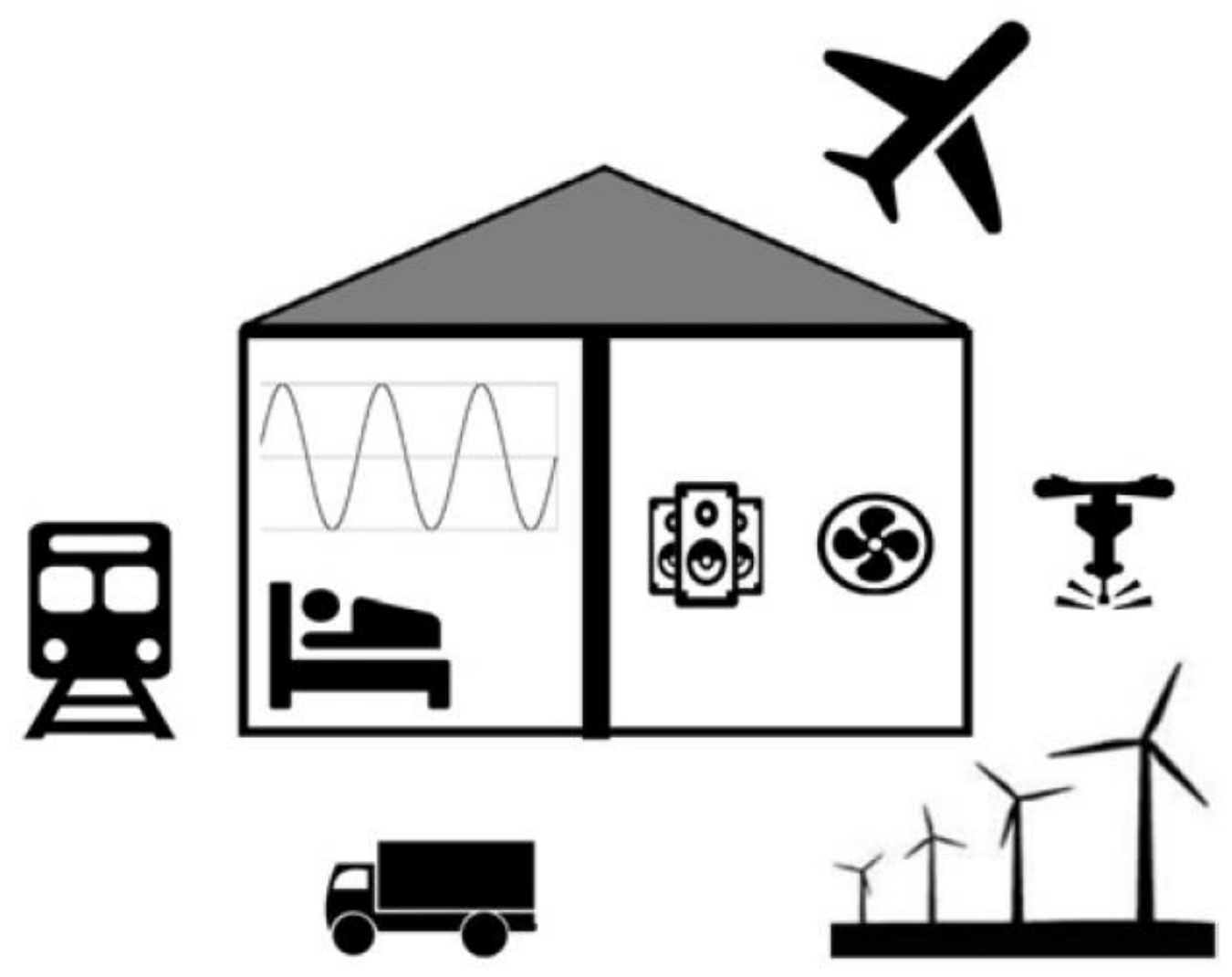

Low-frequency noise in everyday life and health effects:
Many potential sources but little epidemiological research

\section{INTRODUCTION}

Unlike several other environmental stressors, noise pollution, especially in the urban environment, is still increasing (Öhrström et al., 2006; WHO, 2011). Welldocumented evidence supports an association between higher levels of environmental noise and various adverse health effects, such as cardiovascular diseases (Münzel et al., 2014), sleep quality (de Kluizenaar et al., 2009; Omlin et al., 2011; van Kamp and Davies, 2013), annoyance (Miedema and Oudshoorn, 2001; van Kamp et al., 2004; Frei et al., 2014) and also cognitive development and hyperactivity in vulnerable population groups such as children (van Kamp and Davies, 2013; Basner et al., 2014).

Noise ranks among the environmental stressors with the highest public health impact (WHO, 2011) and it is therefore important to regularly monitor for the determination 
Baliatsas, C., Kamp, I. van, Poll, R. van, Yzermans, J. Health effects from low-frequency noise and infrasound in the general population: is it time to listen? A systematic review of

observational studies. Science of the Total Environment: 2016, 557, 163-169

and comprehension of possible effects on health. An underinvestigated noise component in relation to health effects is low frequency noise (LFN) (sound below $250 \mathrm{~Hz}$ ), including infrasound (up to $20 \mathrm{~Hz}$ ) (Berglund et al., 1996; Leventhall, 2004). Although LFN is audible at sufficiently high pressure levels (decibels, dB), it can also occur below the human hearing threshold (Leventhall, 2007), considering that the human ear responds better to sound frequencies between $500 \mathrm{~Hz}$ and $8 \mathrm{kHz}$ (Farina, 2014).

Sounds within the low-frequency sound spectrum comprise a common, everyday-life environmental exposure, produced by natural (sea waves, wind turbulence) as well as by man-made sources (industrial installations, domestic appliances, transportation) sources. The latter constitute the primary cause of LFN (Berglund et al., 1996), while the rapid expansion of infrastructure has increased the attribution of symptoms to LFN and public concern (Jakobsen, 2012). According to earlier evidence from local environmental health authorities, complaints due to LFN comprise about $35 \%$ of the total noise complaints filed (Bengtsson and Waye, 2003). Low frequency noise in the residential environment is described as a constant, deep and humming/rumbling sound and although complainants perceive it with their ears, the perception of bodily or external vibration is also possible (Møller and Lydolf, 2003). Annoyance is usually the first reaction to this type of noise, often accompanied by secondary effects, such as headache, concentration difficulties palpitations and sleep problems (Møller and Lydolf, 2003; Leventhall, 2009).

A number of studies suggest an association between LFN and various physiological and psychological reactions such as annoyance, hearing threshold shift, concentration problems, lower sleep quality, mood effects (Persson Waye et al., 1997; Ising and Ising, 2002; Leventhall, 2004; Pawlaczyk-Łuszczyńska et al., 2005) and also controversial conditions such as the so-called vibro-acoustic disease (Alves-Pereira and Branco, 2007; Chapman and St George, 2013). Additionally, adverse health effects from occupational exposure have been observed on memory, annoyance and performance (Gomes et al., 1999; Persson Waye et al., 2001; Bengtsson et al., 2004; Kaczmarska and Łuczak, 2007; Pawlaczyk-Luszczynska et al., 2009). Evidence on vascular and respiratory effects is inconclusive (Schust, 2004).

Although the potential impact of LFN as environmental pollutant has been highlighted by the WHO (Berglund et al., 1999), current evidence is mainly based on case studies and laboratory experiments of small sample sizes and short exposure sessions (Leventhall, 2009; Ambrose et al., 2012). It is therefore unknown to what extent such health effects occur in relation to everyday-life exposure to LFN at the population level. Observational studies are highly important due to the investigation of everyday-life exposure and effects in larger samples.

No systematic evaluation of the peer-reviewed observational epidemiological literature has been performed up to date on the association between LFN and health. The present paper aims to fill this gap in the literature.

\section{MethodS}

\subsection{Data sources and search}

Pubmed, Embase and PsycInfo were searched as primary databases for relevant studies published between January 1st, 2000 and January 30th, 2015. There was no a-priori language restriction. 
Baliatsas, C., Kamp, I. van, Poll, R. van, Yzermans, J. Health effects from low-frequency noise and infrasound in the general population: is it time to listen? A systematic review of

observational studies. Science of the Total Environment: 2016, 557, 163-169

A wide range of (combined) keywords was used, related to environmental noise exposure and health effects, presented in Table 1. In addition to the electronic database searches, the reference sections of previous systematic reviews and key papers were examined. The databases of the following relevant journals were also searched: Noise and Health, The Journal of the Acoustical Society of America, Journal of Low Frequency Noise, Vibration and Active control, Journal of Environmental Psychology.

\section{[TABLE 1]}

\subsection{Inclusion criteria}

For paper selection, four criteria were used:

I. An exposure criterion. Only studies examining health effects in relation to exposure to low-frequency noise and/or infrasound (up to $250 \mathrm{~Hz}$ ) in the general population were considered as eligible for the review. Exposure characterization based on self-reported questionnaires was considered acceptable as long as this was explicitly stated. Studies on occupational exposure are not covered in this review.

II. A health outcome criterion. Eligible studies should assess any health indicators (e.g annoyance, symptomatic reactions, physical/mental health, wellbeing/quality of life indicators, medical disorders), on the basis of self-reports or objective measures.

III. A population criterion. The eligible studies recruited samples of healthy individuals being at least 15 years old. Studies on individuals with self-reported noise sensitivity were considered eligible as well.

IV. A study criterion. Only peer-reviewed articles of primary observational studies (not re-analyses of outdated data, unpublished reports, conference proceedings, commentaries or reviews), investigating a potential exposure-response relationship were considered as suitable for the present review.

Studies in which exposure was manipulated, such as laboratory studies and "natural experiments", were not included. Case-studies were excluded as well.

\subsection{Procedure}

The literature search, evaluation of inclusion and exclusion criteria, data extraction were conducted by the first author, with uncertainties resolved through consultation with the rest of the co-authors. More specifically:

1) In the first stage the titles and abstracts that were derived from the search process were screened in terms of relevance

2) The hard copies of potentially relevant publications were assessed, using the pre-established inclusion criteria

3) Data were extracted

4) The study quality evaluation was performed independently by the first two authors.

5) Screening for meta-analysis was independently conducted by the first two authors. 
Baliatsas, C., Kamp, I. van, Poll, R. van, Yzermans, J. Health effects from low-frequency noise and infrasound in the general population: is it time to listen? A systematic review of

observational studies. Science of the Total Environment: 2016, 557, 163-169

For each eligible study, the following data were abstracted: Reference and country, study design, sample characteristics and response rate, source of noise and exposure assessment, outcome assessment, variables included as potential confounders, source of funding, and statistically significant exposure-outcome associations.

\subsection{Study quality assessment}

A combined indicator of study quality was developed, based on criteria of methodological bias (exposure misclassification, selection bias, confounding) in observational research (Grimes and Schulz, 2002) and the adequacy of information provided in each article (e.g regarding study design, participant recruitment and characteristics, methodology for the assessment of exposure and outcome, statistical analysis) (STROBE statement, Von Elm et al., 2007). The rating method was qualitative and similar to schemes applied in previous systematic evaluations of the observational literature (Baliatsas et al., 2012). This evaluation was conducted aposteriori and was not a prerequisite for the consideration of a study as eligible for the review.

\subsection{Screening studies for meta-analysis}

After data extraction and quality evaluation, the included studies were screened for meta-analysis suitability. The following possibilities were examined:

1) Conducting a descriptive meta-analysis, to estimate the prevalence of people highly annoyed by LFN, irrespective of noise exposure levels. Only two eligibility criteria were considered, in the absence of assessment of etiological associations: First, studies had to assess high subjective annoyance due to LFN or infrasound; second, the raw prevalence estimates of annoyance had to be provided in the papers or be derivable.

2) Performance of a causal meta-analysis, to gain more insight into the association between everyday life exposure to LFN and health effects.

Study eligibility criteria were the assessment of similar outcomes based on comparable measures and employment of similar methodology to assess exposure to LFN. In addition, effect estimates of the reported associations had to be available in the articles, or at least derivable. Finally, studies with a low score on one or more of the quality assessment categories would be excluded from the meta-analysis.

Analyses were carried out using Comprehensive Meta-analysis (Version 2.2, Biostat, Englewood, NJ).

\section{RESULTS}

\subsection{Literature search and study characteristics}

Fig. 1 illustrates the literature search process. We examined 4014 citations in total and based on our criteria we identified 7 observational studies on the association between everyday life exposure to LFN and health effects (Table 2). All studies were of cross-sectional design and most of them were conducted in Europe $(n=4)$.

\section{[TABLE 2][FIGURE 1]}

Response rates were reported in 6 studies, ranging from $71 \%$ to $93 \%$. Noise sources of primary concern in the investigation were ventilation systems, neighborhood/road traffic, wind turbines and aircrafts. The vast majority of the included studies used 
Baliatsas, C., Kamp, I. van, Poll, R. van, Yzermans, J. Health effects from low-frequency noise and infrasound in the general population: is it time to listen? A systematic review of

observational studies. Science of the Total Environment: 2016, 557, 163-169

objective measurements to assess LFN $(n=6)$ such as spot measurements and sound propagation models. In two of these studies, exposure assessment was solely relied on A-weighting. The most frequently examined outcome was subjective annoyance $(n=4)$. All studies assessed health outcomes using self-reported questionnaires.

\subsection{Association between everyday life LFN exposure and health effects}

As shown in Table 2, two studies suggested a significant association between LFN and annoyance. Significant associations or between-group ("exposed" vs. reference group) differences were also observed for outcomes such as hypertension, heart palpitations, concentration problems and sleep-related problems. Age and gender were the most examined potential confounders. Study quality appeared to be moderate for the majority of the examined studies, on the basis of the provision of information in each article and the methodology followed to assess the LFN exposure-outcome associations (Table 3). Overall, among the most important limitations were insufficient adjustment for confounders, use of A-weighting, selfreported assessment of exposure and small sample sizes.

\section{[TABLE 3]}

\subsection{Data synthesis: pooled prevalence of high annoyance in the population}

Regarding the descriptive meta-analysis, four studies provided data to calculate perstudy and pooled raw prevalence of high levels of subjective annoyance attributed to LFN. The studies were all performed among people living in the vicinity of some LFN source, be it an airport, wind turbines, or installations at home producing LFN/infrasound.

To summarize the prevalence estimates, DerSimonian-Laird random-effects metaanalysis (DerSimonian and Laird, 1986) was performed, considering heterogeneity among the studies, which was verified using the $\mathrm{I}^{2}$ statistic (Higgins et al., 2003) $\left(\mathrm{I}^{2}=27.6 \%\right)$. Prevalence statistics were described based on the event rate.

Ninety-five percent confidence intervals (CIs) were calculated using the sample size (n) and standard error. Prevalence of high annoyance in the studies varied between $2 \%$ and $34 \%$ with a pooled prevalence of $10.5 \%$ as shown in Table 4. Publication bias was not apparent as assessed by the Egger's test (Egger et al., 1997), which was not significant $(p=0.32)$.

Table 4. Prevalence of high self-reported annoyance attributed to LFN, based on data from observational studies.

Abbreviations: CI, confidence interval.

Taking all the eligibility parameters into account, it was not feasible to perform a causal meta-analysis on the association between exposure to LFN and health outcomes.

\section{DISCUSSION}

\subsection{Primary findings}

This systematic review identified the observational epidemiological studies undertaken the past fifteen years on the association between everyday life LFN, including infrasound, and health effects in the general population. A descriptive meta-analysis was carried out as a first effort to estimate the pooled prevalence of high annoyance attributed to LFN at the level of the adult population living in the 
Baliatsas, C., Kamp, I. van, Poll, R. van, Yzermans, J. Health effects from low-frequency noise and infrasound in the general population: is it time to listen? A systematic review of observational studies. Science of the Total Environment: 2016, 557, 163-169

vicinity of some source of LFN. The review showed some associations between exposure to LFN sources and self-reported annoyance and various neurological symptoms such as sleep-related problems, concentration difficulties and headache. Inconsistency across studies and the small number of existing observational investigations prevents us from a direct comparison with experimental evidence (Leventhall, 2009). The pooled analysis on prevalence of subjective annoyance showed that, independently of the exposure levels, a considerable number of people living in the vicinity of noise sources attribute high annoyance to LFN. However, there is still very limited risk-assessment research in the field of LFN and health effects. More research should be undertaken in several directions, investigating health effects of objectively measured LFN from different, widespread and emerging, sources in everyday life. This requires serious methodological considerations regarding exposure characterization and outcome assessment.

\subsection{Strengths and limitations}

The strengths of this paper include a rigorous search strategy, consideration of different LFN sources, study quality assessment and the estimation of prevalence of high annoyance attributed to LFN components in the included studies. Among the limitations are the relatively small number of eligible studies, small sample sizes, the overall moderate quality of evidence and between-study heterogeneity, especially in relation to outcome measures. The fact that most studies only investigated selfreported symptoms in relation to exposure, limits the conclusions that could be drawn regarding other (long-term) health effects. Finally, methodological differences and study quality issues prevented us from conducting a causal meta-analysis.

\subsection{Methodological considerations and implications for future research}

An issue of importance in terms of exposure characterization is the weighting method used to measure LFN. A-weighting is widely used in public health research. Adapted to the sensitivity of the average human ear, sound level meters set to the Aweighting scale cannot efficiently evaluate the contribution of LFN components, since the human ear is less sensitive to very low-pitch or high-pitch noises (Farina, 2014). As a result, LFN levels are suppressed by A-weighted measures, which can lead to exposure misclassification (Farina, 2014; Ascari et al., 2015). Exposure assessment protocols for population research incorporating this aspect still need to be developed and applied. Use of personal exposure measurements apart from timeconsuming is costly and therefore may not be feasible for large epidemiological studies. Exposure prediction models could be a cost-efficient approach, however, there is not enough evidence on the accuracy of low frequency mapping while large heterogeneity exists among the proposed methods (Ascari et al., 2015). An important aspect for investigation could also be the contrast or overlap between perceived and actual noise levels. Previous research on other environmental exposures such as to electromagnetic fields (EMF) has shown that objectively measured and perceived exposures do not always correspond and this could have major implications for the mechanisms that lead to symptom report (Baliatsas et al., 2015).

Studies of longitudinal design assessing exposure-outcome patterns over time and intervention studies of large samples in which manipulation of LFN levels could be examined in relation to health effects, would help us determine the causal mechanisms involved. Considering that most of the existing studies have been focusing on annoyance, outcome assessment should be expanded to more acute as 
Baliatsas, C., Kamp, I. van, Poll, R. van, Yzermans, J. Health effects from low-frequency noise and infrasound in the general population: is it time to listen? A systematic review of

observational studies. Science of the Total Environment: 2016, 557, 163-169

well as long-term health effects based on validated instruments. Especially regarding chronic disorders, the combination of self-reported and electronic medical record data would provide reliable information into clinically relevant characteristics of the respondents and minimize the risk for biases such as outcome misclassification and selection bias. Furthermore, it is a challenge to determine the exact role of annoyance in relation to health effects of LFN, both conceptually and explanatorily; for instance, as a health outcome and/or an indicator of secondary health effects and future morbidity.

Given the various non-acoustic factors that play a role in reactions to noise (Stansfeld and Shipley, 2015), not only exposure levels that could be related to health effects are of importance, but also the confounding, mediating and/or moderating role individual aspects such as sociodemographic characteristics, noise sensitivity, environmental worries, perceived control over environmental stressors, coping strategies and somatic morbidity and somatoform disorders (van Kamp, 1990; van Kamp et al., 2004; Bailer et al., 2005; Page et al., 2006; Baliatsas et al., 2015). In addition, whether symptomatic reactions to LFN can be considered a manifestation of noise sensitivity is worthy of further investigation. Noise-sensitive groups are underrepresented in study populations and evidence on differential characteristics is scarce (van Kamp et al., 2013).

Finally, the publication of technical and health reports in peer-reviewed public health journals should be encouraged, since relevant studies of potential added value in the grey literature are difficult to identify, access and/or assess.

Moreover, as long as uncertainty regarding health effects from LFN remains, effective risk communication with the public is needed, acknowledging the worries of the affected citizens and facilitating access to the latest research findings.

\section{CONCLUSIONS}

Evidence from the present systematic evaluation of observational studies suggests an association between exposure to LFN components and self-reports of annoyance and various symptoms in the population. However, results should be interpreted with caution due to the small number of existing studies. An association with other health effects might exist, but evidence is still limited and inconclusive. More epidemiological research is imperative, involving larger samples and better methodological quality in terms of exposure and outcome assessment. This will also make feasible the performance of future meta-analytic studies.

\section{CONFLICT OF INTEREST}

None declared.

\section{ACKNOWLEDGEMENTS}

The present paper was written within the framework of the updated LFN guidelines of the Dutch Municipal Health Services. The authors would like to thank Annelike Dusseldorp, Rita Slob and our colleagues at NIVEL for their feedback on the paper, especially Tessa Magnée and Dolf de Boer.

\section{REFERENCES}


Baliatsas, C., Kamp, I. van, Poll, R. van, Yzermans, J. Health effects from low-frequency noise and infrasound in the general population: is it time to listen? A systematic review of observational studies. Science of the Total Environment: 2016, 557, 163-169

M. Alves-Pereira, N.A.C. BrancoVibroacoustic disease: biological effects of infrasound and low-frequency noise explained by mechanotransduction cellular signallingProg. Biophys. Mol. Biol., 93 (2007), pp. 256-279

S.E. Ambrose, R.W. Rand, C.M. KroghWind turbine acoustic investigation infrasound and low-frequency noise-a case studyBull. Sci. Technol. Soc., 32 (2012), pp. 128-141

E. Ascari, G. Licitra, L. Teti, M. CerchiaiLow frequency noise impact from road traffic according to different noise prediction methodsSci. Total Environ., 505 (2015), pp. 658-669

J. Bailer, M. Witthöft, C. Paul, C. Bayerl, F. RistEvidence for overlap between idiopathic environmental intolerance and somatoform disordersPsychosom. Med., 67 (2005), pp. 921 929

C. Baliatsas, I. Van Kamp, J. Bolte, M. Schipper, J. Yzermans, E. LebretNon-specific physical symptoms and electromagnetic field exposure in the general population: can we get more specific? A systematic reviewEnviron. Int., 41 (2012), pp. 15-28

C. Baliatsas, J. Bolte, J. Yzermans, G. Kelfkens, M. Hooiveld, E. Lebret, et al.Actual and perceived exposure to electromagnetic fields and non-specific physical symptoms: an epidemiological study based on self-reported data and electronic medical recordsInt. J. Hyg. Environ. Health, 218 (2015), pp. 331-344

M. Basner, W. Babisch, A. Davis, M. Brink, C. Clark, S. Janssen, et al.Auditory and nonauditory effects of noise on healthLancet, 383 (2014), pp. 1325-1332

J. Bengtsson, K.P. WayeAssessments of low frequency noise complaints among the local Environmental Health Authorities and a follow-up study 14 years laterJ. Low Freq. Noise V. A., 22 (2003), pp. 9-16

J. Bengtsson, K.P. Waye, A. KjellbergEvaluations of effects due to low-frequency noise in a low demanding work situationJ. Sound Vib., 278 (2004), pp. 83-99

B. Berglund, P. Hassmen, R.S. JobSources and effects of low-frequency noiseJ. Acoust. Soc. Am., 99 (1996), pp. 2985-3002

B. Berglund, T. Lindvall, D.H. SchwelaGuidelines for community noiseGuidelines for community noise, OMS (1999)

T.Y. Chang, R. Beelen, S.F. Li, T.I. Chen, Y.J. Lin, B. Bao, et al.Road traffic noise frequency and prevalent hypertension in Taichung, Taiwan: a cross-sectional studyEnviron. Health, 13 (2014), p. 37

S. Chapman, A. St GeorgeHow the factoid of wind turbines causing 'vibroacoustic disease' came to be 'irrefutably demonstrated'Aust. N. Z. J. Public Health, 37 (2013), pp. 244-249

Y. de Kluizenaar, S.A. Janssen, F.J. van Lenthe, H.M. Miedema, J.P. MackenbachLong-term road traffic noise exposure is associated with an increase in morning tirednessJ. Acoust. Soc. Am., 126 (2009), pp. 626-633

R. DerSimonian, N. LairdMeta-analysis in clinical trialsControl. Clin. Trials, 7 (1986), pp. 177188

A. Dzhambov, D. DimitrovaNeighborhood noise pollution as a determinant of displaced aggression: a pilot studyNoise Health, 16 (2014), p. 95

M. Egger, G.D. Smith, A.N. PhillipsMeta-analyses: principles and proceduresBMJ, 315 (1997), p. 1533

A. FarinaSoundscape EcologySpringer, Dordrecht, NL (2014)

S. Fidell, K. Pearsons, L. Silvati, M. SneddonRelationship between low-frequency aircraft noise and annoyance due to rattle and vibrationJ. Acoust. Soc. Am., 111 (2002), pp. 17431750

P. Frei, E. Mohler, M. RöösliEffect of nocturnal road traffic noise exposure and annoyance on objective and subjective sleep qualitylnt. J. Hyg. Environ. Health, 217 (2014), pp. 188195

L.M.P. Gomes, A.J.F. Martinho Pimenta, N.A.A. Castelo BrancoEffects of occupational exposure to low frequency noise on cognitionAviat. Space Environ. Med., 70 (1999), pp. A115-A118

D.A. Grimes, K.F. SchulzBias and causal associations in observational researchThe Lancet, 359 (2002), pp. 248-252

J.P. Higgins, S.G. Thompson, J.J. Deeks, D.G. AltmanMeasuring inconsistency in metaanalysesBr. Med. J., 327 (2003), p. 557

$\mathrm{H}$. Ising, M. IsingChronic cortisol increases in the first half of the night caused by road traffic noiseNoise Health, 4 (2002), p. 13 
Baliatsas, C., Kamp, I. van, Poll, R. van, Yzermans, J. Health effects from low-frequency noise and infrasound in the general population: is it time to listen? A systematic review of observational studies. Science of the Total Environment: 2016, 557, 163-169

J. JakobsenDanish regulation of low frequency noise from wind turbinesJ. Low Freq. Noise V. A., 31 (2012), pp. 239-246

A. Kaczmarska, A. ŁuczakA study of annoyance caused by low-frequency noise during mental workInt. J. Occup. Saf. Ergon., 13 (2007), pp. 117-125

H.G. LeventhallLow frequency noise and annoyanceNoise Health, 6 (2004), p. 59

G. LeventhallWhat is infrasound?Prog. Biophys. Mol. Biol., 93 (2007), pp. 130-137

G. LeventhallReview: low frequency noise. What we know, what we do not know, and what we would like to knowNoise Notes, 8 (2009), pp. 3-28

S.R. Magari, C.E. Smith, M. Schiff, A.C. RohrEvaluation of community response to wind turbine-related noise in Western New York StateNoise Health, 16 (2014), p. 228

H.M. Miedema, C.G. OudshoornAnnoyance from transportation noise: relationships with exposure metrics DNL and DENL and their confidence intervalsEnviron. Health Perspect., 109 (2001), p. 409

$\mathrm{H}$. Møller, M. LydolfA questionnaire survey of complaints of infrasound and low-frequency noiseNoise Notes, 2 (2003), pp. 3-12

T. Münzel, T. Gori, W. Babisch, M. BasnerCardiovascular effects of environmental noise exposureEur. Heart J., 35 (2014), pp. 829-836

R.M. Niven, A.M. Fletcher, C.A.C. Pickering, E.B. Faragher, I.N. Potter, W.B. Booth, et al.Building sickness syndrome in healthy and unhealthy buildings: an epidemiological and environmental assessment with cluster analysisOccup. Environ. Med., 57 (9) (2000), pp. 627-634

E. Öhrström, A. Skånberg, H. Svensson, A. Gidlöf-GunnarssonEffects of road traffic noise and the benefit of access to quietnessJ. Sound Vib., 295 (2006), pp. 40-59

S. Omlin, G.F. Bauer, M. BrinkEffects of noise from non-traffic-related ambient sources on sleep: review of the literature of 1990-2010Noise Health, 13 (2011), p. 299

L.A. Page, K.J. Petrie, S.C. WesselyPsychosocial responses to environmental incidents: a review and a proposed typologyJ. Psychosom. Res., 60 (2006), pp. 413-422

M. Pawlaczyk-Łuszczyńska, A. Dudarewicz, M. Waszkowska, W. Szymczak, M. Kameduła, M. Śliwińska-KowalskaDoes low frequency noise at moderate levels influence human mental performance?J. Low Freq. Noise V. A., 24 (2005), pp. 25-42

M. Pawlaczyk-Luszczynska, A. Dudarewicz, M. Waszkowska, M. SliwinskaKowalskaAnnoyance related to low frequency noise in subjective assessment of workersJ. Low. Freq. Noise V. A., 28 (2009), pp. 1-17

P. Persson Waye, R. RylanderThe prevalence of annoyance and effects after long-term exposure to low-frequency noiseJ. Sound Vib., 240 (2001), pp. 483-497

P. Persson Waye, R. Rylander, S. Benton, H.G. LeventhallEffects on performance and work quality due to low frequency ventilation noiseJ. Sound Vib., 20 (1997), pp. 467-474

P. Persson Waye, J. Bengtsson, A. Kjellberg, S. BentonLow frequency "noise pollution" interferes with performanceNoise Health, 4 (2001), p. 33

K. Persson Waye, J. Bengtsson, A. Agge, M. BjorkmanA descriptive cross-sectional study of annoyance from low frequency noise installations in an urban environmentNoise Health, 5 (2003), p. 35

M. SchustEffects of low frequency noise up to $100 \mathrm{HzNoise}$ Health, 6 (2004), p. 73

S.A. Stansfeld, M. ShipleyNoise sensitivity and future risk of illness and mortalitySci. Total Environ., 520 (2015), pp. 114-119

I. van KampCoping with noise and its health consequencesDoctoral Dissertation, University of Groningen (1990)

I. van Kamp, H. DaviesNoise and health in vulnerable groups: a reviewNoise Health, 15 (2013), p. 153

I. van Kamp, R.S. Job, J. Hatfield, M. Haines, R.K. Stellato, S.A. StansfeldThe role of noise sensitivity in the noise-response relation: a comparison of three international airport studiesJ. Acoust. Soc. Am., 116 (2004), pp. 3471-3479

I. van Kamp, E. van Kempen, C. Baliatsas, D. HouthuijsMental health as context rather than health outcome of noise: Competing hypotheses regarding the role of sensitivity, perceived soundscapes and restorationProceedings of the International Congress on Noise Control Engineering (Internoise), 247 (2013), pp. 3804-3811 
Baliatsas, C., Kamp, I. van, Poll, R. van, Yzermans, J. Health effects from low-frequency noise and infrasound in the general population: is it time to listen? A systematic review of observational studies. Science of the Total Environment: 2016, 557, 163-169

E. Von Elm, D.G. Altman, M. Egger, S.J. Pocock, P.C. Gøtzsche, J.P. Vandenbroucke, et al.The Strengthening the Reporting of Observational Studies in Epidemiology (STROBE) statement: guidelines for reporting observational studiesPrev. Med., 45 (2007), pp. 247-251

\section{TABLES AND FIGURES}

\section{Table 1}

Key search terms.

Outcome Physical symptoms, somatic symptoms, health symptoms, health problems, health effects, neurological symptoms, ill health, well-being, quality of life, annoyance, disturbance, discomfort, sleep quality, sleep disturbance, sleep problems, insomnia, impairment, tinnitus, vertigo, nausea, balance problems, respiratory effects, respiratory problems, vibroacoustic disease, stress, irritation, attributed symptoms, fatigue, aural pain, palpitations, cardiovascular

Exposure Noise pollution, environmental noise, noise exposure, perceived noise, noise sensitivity, noise susceptibility, auditory sensitivity, neighborhood noise, infrastructure noise, wind turbines, compressors, wind farms, ventilation noise, power lines, transmission lines, industrial noise, electrical installations, amplified music, blasting, pumps, air-conditioning, refrigerators, fans, boilers, heating system, gas pipelines, radio sound, radio noise, impulse sound, perceived sound, transportation noise, trains, rail traffic, railway noise, air traffic noise, airport noise, aircraft noise, traffic noise, road traffic noise, cooling towers, sewerage, residential noise, domestic noise, low frequency noise, low frequency sound, If noise, infrasound, ambient noise, background noise

Design Observational, cross-sectional, cohort, case-control, population-based Time January 2000-January 2015 period 
Baliatsas, C., Kamp, I. van, Poll, R. van, Yzermans, J. Health effects from low-frequency noise and infrasound in the general population: is it time to listen? A systematic review of observational studies. Science of the Total Environment: 2016, 557, 163-169

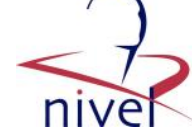

Search for peer-reviewed articles published between January 2000 \& January 2015

4014 articles identified in total:

- 1582 from Embase

- 1181 from Psyclnfo

- 1112 from Pubmed

- 139 from reference sections of research articles, reviews \& journal databases
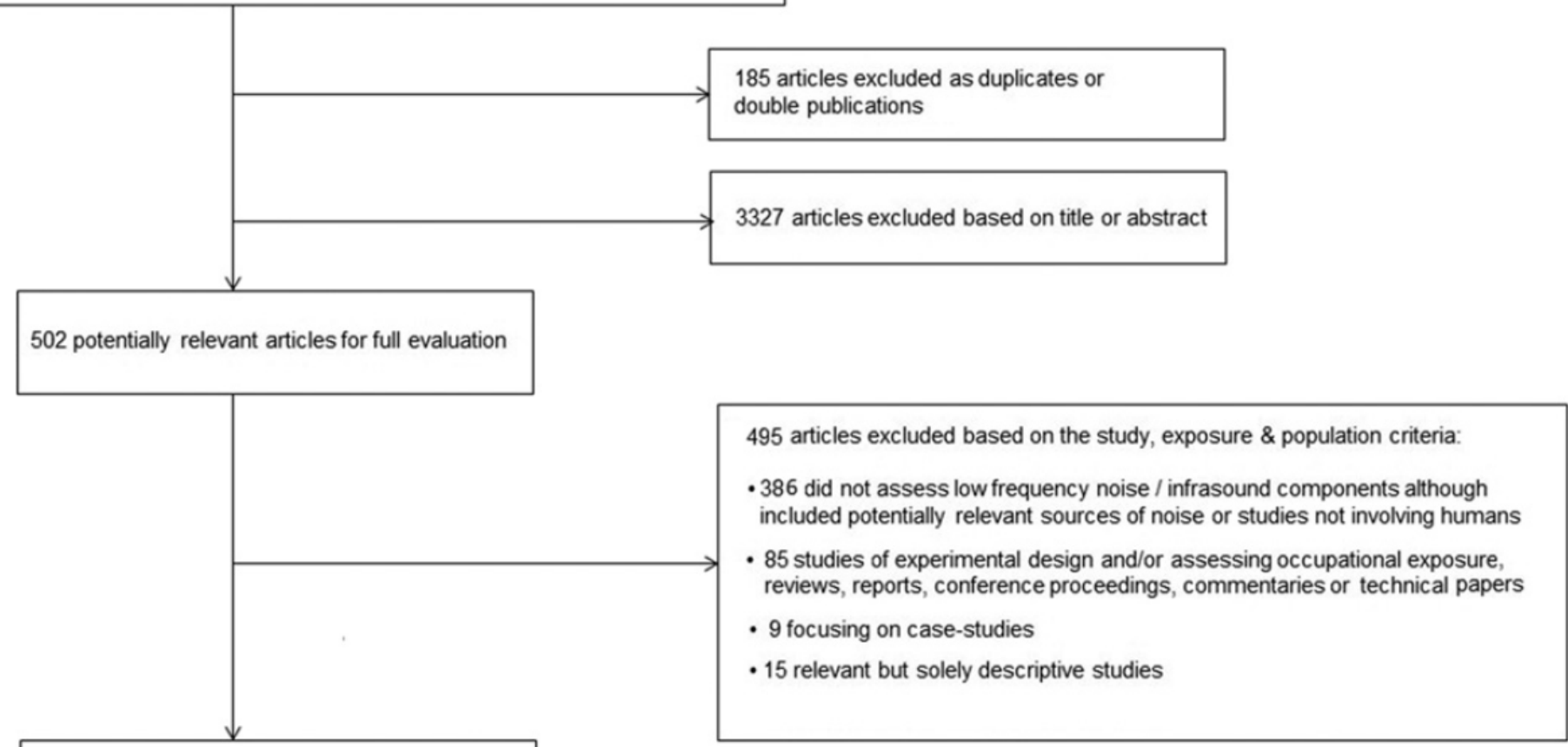

7 articles eligible for the review

Fig. 1. Flow diagram outlining the study selection process. 
Baliatsas, C., Kamp, I. van, Poll, R. van, Yzermans, J. Health effects from low-frequency noise and infrasound in the general population: is it time to listen? A systematic review of observational studies. Science of the Total Environment: 2016, 557, 163-169

\section{Table 3}

Quality assessment of observational studies on the association between LFN and health effects.

\begin{tabular}{lll}
\hline Reference & $\begin{array}{l}\text { Provided } \\
\text { information }^{\text {a }}\end{array}$ & $\begin{array}{l}\text { Risk for methodological } \\
\text { bias }^{\text {b }}\end{array}$ \\
\hline Niven et al. (2000) & ++ & ++ \\
Persson Waye and Rylander (2001) & +++ & ++ \\
Fidell et al. (2002) & + & ++ \\
Persson Waye et al. (2003) & ++ & +++ \\
Chang et al. (2014) & +++ & + \\
Dzhambov and Dimitrova (2014) & ++ & +++ \\
Magari et al. (2014) & ++ & ++ \\
\hline
\end{tabular}

a + low score, ++ medium score, +++ high score.

b + lower risk, ++ medium risk, +++ higher risk. 
Table 2

Observational studies on the association between LFN and infrasound exposure and health effects.

\begin{tabular}{|c|c|c|c|c|c|c|c|}
\hline $\begin{array}{l}\text { Reference \& } \\
\text { country }\end{array}$ & Study design & $\begin{array}{l}\text { Sample characteristics } \\
\text { (response rate) }\end{array}$ & $\begin{array}{l}\text { Noise source(s) \& } \\
\text { exposure assessment } \\
\text { (objective vs. }^{\text {self-reported) }}{ }^{\mathrm{a}}\end{array}$ & $\begin{array}{l}\text { Outcome } \\
\text { assessment }\end{array}$ & $\begin{array}{l}\text { Variables considered as } \\
\text { possible confounders }\end{array}$ & $\begin{array}{l}\text { Funding } \\
\text { source }\end{array}$ & $\begin{array}{l}\text { Statistically significant } \\
\text { associations }\end{array}$ \\
\hline $\begin{array}{l}\text { Niven et al. } \\
\text { (2000), } \\
\text { UK }\end{array}$ & Cross-sectional & $\begin{array}{l}947 \text { ( } 80 \%) \text { subjects with } \\
\text { m.a }=35.2, \text { working in } \\
\text { five buildings (three } \\
\text { air-conditioned } \\
\text { buildings, one naturally } \\
\text { ventilated \& one } \\
\text { considered as "sick } \\
\text { building". F.g }=49 \% .\end{array}$ & $\begin{array}{l}\text { LFN from air } \\
\text { conditioning }(0) \text {, spot } \\
\text { measurements, } \\
\text { maximum frequency } \\
\text { level: } 63 \mathrm{~Hz} \text {, A-weighted } \\
\text { SPL, Leq } 24 \mathrm{~h} \text { range in } \\
\text { buildings }=40-74 \mathrm{~dB} \text {. }\end{array}$ & $\begin{array}{l}\text { Self-reported } \\
\text { questionnaire on } \\
\text { various } \\
\text { non-specific } \\
\text { physical symptoms. }\end{array}$ & Not reported & Unspecified & $\begin{array}{l}\text { Pooled data from all } \\
\text { buildings: itchy eyes ( } p= \\
0.001) \text {, stuffy nose, dry skin } \\
(p<0.01) \text {. Data from the } \\
\text { "Sick building": Runny } \\
\text { nose }(p=0.001) \text {, stuffy } \\
\text { nose }(p=0.01) \text { headache, } \\
\text { lethargy }(p<0.01) \text {. }\end{array}$ \\
\hline $\begin{array}{l}\text { Persson } \\
\text { Waye and } \\
\text { Rylander } \\
\text { (2001), } \\
\text { Sweden }\end{array}$ & Cross-sectional & $\begin{array}{l}279(83 \%) \text { randomly } \\
\text { selected subjects } 18-75 \\
\text { y.o. Six homogeneous } \\
\text { residential areas } \\
\text { selected, exposed to } \\
\text { either residential LFN } \\
\text { sources or } \\
\text { mid-frequency noise } \\
\text { (control areas). }\end{array}$ & $\begin{array}{l}\text { Heat pumps or heat } \\
\text { pump/ventilation } \\
\text { systems }(0), \text { Spot } \\
\text { measurements, } \\
\text { Frequency spectra in } \\
\text { LFN-exposed areas at } \\
50-200 \mathrm{~Hz}, \mathrm{~A}-, \mathrm{B}-\mathrm{\&} \\
\text { C-weighted SPL, range } \\
\text { dB exposed vs. controls: } \\
\mathrm{dB}(\mathrm{B})=31-38 \text { vs. } \\
40-51 ; \mathrm{dB}(\mathrm{C})=41-49 \\
\text { vs. } 49-60 ; \mathrm{dB}(\mathrm{A}) \text { Leq } 24 \mathrm{~h} \\
=44-47 \text { vs. } 44-49 .\end{array}$ & $\begin{array}{l}\text { Self-reported } \\
\text { questionnaire } \\
\text { assessing } \\
\text { annoyance levels \& } \\
\text { various physical } \\
\text { and psychological } \\
\text { symptoms. }\end{array}$ & $\begin{array}{l}\text { Not reported (there was } \\
\text { similar distribution in } \\
\text { terms of age, gender, } \\
\text { noise sensitivity, family } \\
\text { status, chronic illness, } \\
\text { employment status \& } \\
\text { workload between } \\
\text { subjects in the exposed \& } \\
\text { control areas). }\end{array}$ & Unspecified & $\begin{array}{l}\text { Prevalence range in } \\
\text { different exposed vs. } \\
\text { unexposed areas: } \\
\text { Annoyance, } 14.7 \%-20 \% \text {, } \\
\text { vs. } 3.4 \%-4.2 \%(p<0.05) \text {; } \\
\text { disturbed concentration, } \\
\text { 7.5\%-17.5\% vs. } 0 \% \text { ( } p< \\
0.05) \text {; disturbed } \\
\text { rest/relaxation, } \\
12.5 \%-22 \% \text { vs. } 0 \%-0.7 \% \text {, } \\
(p<0.05) \text {. }\end{array}$ \\
\hline $\begin{array}{l}\text { Persson } \\
\text { Waye } \\
\text { et al. } \\
\text { (2003), } \\
\text { Sweden }\end{array}$ & Cross-sectional & $\begin{array}{l}41(71 \%) \text { randomly } \\
\text { selected subjects } 18-80 \\
\text { y.o living in blocks of } \\
\text { flats with one side facing } \\
\text { a street with high traffic } \\
\text { (comparison group) and } \\
\text { the other side facing a } \\
\text { courtyard full of } \\
\text { domestic LFN sources } \\
\text { (exposed group) }\end{array}$ & $\begin{array}{l}\text { Fans, compressors, } \\
\text { air-cooling systems }(\mathrm{O}) \text {, } \\
\text { Spot measurements, } \\
\text { frequency spectra at } \geq 20 \\
\mathrm{~Hz}, \mathrm{~A}-\& \text { C-weighted SPL, } \\
\text { Leq24h in whole area: } \\
\mathrm{dB}(\mathrm{A})=31 \text { (windows } \\
\text { closed) \& } 43 \text { (windows } \\
\text { slightly opened); dB }(\mathrm{C}) \\
=50 \text { (windows closed) } \\
\text { \& } 56 \text { (windows slightly } \\
\text { opened). }\end{array}$ & $\begin{array}{l}\text { Self-reported } \\
\text { questionnaire } \\
\text { assessing } \\
\text { disturbance from } \\
\text { different } \\
\text { environmental } \\
\text { stressors, } \\
\text { annoyance levels, } \\
\text { sleep quality \& } \\
\text { perceived health }\end{array}$ & $\begin{array}{l}\text { Not reported (no } \\
\text { statistically significant } \\
\text { difference between } \\
\text { exposed and controls in } \\
\text { terms of age, gender, and } \\
\text { socio-economic status. }\end{array}$ & Unspecified & N.S. \\
\hline $\begin{array}{l}\text { Fidell et al. } \\
\text { (2002), } \\
\text { USA }\end{array}$ & Cross-sectional & $\begin{array}{l}495 \text { ( } 81 \%) \text { subjects } \geq 18 \mathrm{y} \text {. } \\
\text { o, living in a residential } \\
\text { area close an airport. }\end{array}$ & $\begin{array}{l}\text { Aircraft }(0), \text { spot } \\
\text { measurements (digital } \\
\text { recordings), Frequency } \\
\text { spectra at } 25-80 \mathrm{~Hz} \text {, } \\
\text { C-weighted SPL, mean } \\
\text { dB range in different } \\
\text { areas }=77.5-86.9 .\end{array}$ & $\begin{array}{l}\text { Telephone } \\
\text { interviews } \\
\text { assessing } \\
\text { annoyance levels. }\end{array}$ & Not reported & Public & $\begin{array}{l}\text { Annoyance prevalence } \\
\text { per midpoint of LFN } \\
\text { exposure interval: } 21.6 \% \\
(77.5 \mathrm{~dB}), 36.8 \% \text { ( } 87.5 \\
\text { dB) }\end{array}$ \\
\hline $\begin{array}{l}\text { Chang et al. } \\
\text { (2014), } \\
\text { Taiwan }\end{array}$ & Cross-sectional & $\begin{array}{l}820 \text { subjects living near } \\
\text { main roads for more than } \\
3 \text { years with m.a }=36 \\
\text { ( } 774 \text { controls). F.g }= \\
51 \% .\end{array}$ & $\begin{array}{l}\text { Road traffic }(0), \text { Spot } \\
\text { measurements, } \\
\text { frequency spectra at } \\
31.5-125 \mathrm{~Hz} \text {, } \\
\text { A-weighted SPL, highest } \\
\text { median: } 61 \mathrm{~dB} \text { at } 1000 \\
\mathrm{~Hz} \text {, lowest median: } 27 \\
\mathrm{~dB} \text { at } 31.5 \mathrm{~Hz} \text {. }\end{array}$ & $\begin{array}{l}\text { Identification of } \\
\text { cases of } \\
\text { hypertension based } \\
\text { on standardized } \\
\text { interviews. }\end{array}$ & $\begin{array}{l}\text { Age, gender, body mass } \\
\text { index and family history } \\
\text { of hypertension, } \\
\text { cigarette smoking, } \\
\text { alcohol consumption, } \\
\text { high salt intake and } \\
\text { physical inactivity, total } \\
\text { traffic flow rate }\end{array}$ & Public & $\begin{array}{l}\text { Hypertension: at } 63 \mathrm{~Hz} \text {, } \\
\text { median: } 41 \mathrm{~dB}(\mathrm{OR}=2.77 \text {, } \\
95 \% \mathrm{CI}=1.17-6.52) \text {, at } 125 \\
\mathrm{~Hz}, \text { median: } 49 \mathrm{~dB}(4.08, \\
95 \% \mathrm{CI}=1.57-10.63) \text {. At } \\
125 \mathrm{~Hz} \text {, subjects exposed to } \\
\geq 51 \mathrm{~dB} \text { vs. those exposed to } \\
<47 \mathrm{~dB}: \mathrm{OR}=4.65 \text { ( } 95 \% \mathrm{CI} \\
=1.46-14.83) .\end{array}$ \\
\hline $\begin{array}{l}\text { Dzhambov } \\
\text { and } \\
\text { Dimitrova } \\
\text { (2014), } \\
\text { Bulgaria }\end{array}$ & Cross-sectional & $\begin{array}{l}182 \text { ( } 84 \%) \text { subjects with } \\
\text { m.a }=36.9 \text {, living in a } \\
\text { non-industrial area with } \\
\text { high levels of } \\
\text { traffic/neighborhood } \\
\text { noise, based on noise } \\
\text { monitoring Municipality } \\
\text { data. F.g }=45 \% \text {. }\end{array}$ & $\begin{array}{l}\text { Outdoor/neighborhood } \\
\text { (S). }\end{array}$ & $\begin{array}{l}\text { Semi-structured } \\
\text { interview survey, } \\
\text { assessing displaced } \\
\text { aggression. }\end{array}$ & $\begin{array}{l}\text { Age, years of residency, } \\
\text { perceived noise sensitivity, } \\
\text { continuous/intermittent } \\
\text { noise exposure, frequency } \\
\text { of hearing noises above } \\
\text { normal threshold, } \\
\text { interaction age } * \text { years of } \\
\text { residency }\end{array}$ & Unspecified & $\begin{array}{l}\text { Displaced aggression }(p< \\
0.001)\end{array}$ \\
\hline $\begin{array}{l}\text { Magari et al. } \\
\text { (2014), } \\
\text { USA }\end{array}$ & Cross-sectional & $\begin{array}{l}62(93 \%) \text { subjects with } \\
\text { m.a }=36.9, \text { living in and } \\
\text { around a wind park. F.g } \\
=43.5 \%\end{array}$ & $\begin{array}{l}\text { Indoor \& outdoor LFN } \\
(20-250 \mathrm{~Hz}) \& \\
\text { infrasound }(6.3-16 \mathrm{~Hz}) \\
\text { from wind turbines }(\mathrm{O}) \text {, } \\
\text { sport measurements, } \\
\text { unweighted SPL, } \\
\text { Leq10-min = 56.9 for } \\
\text { LFN \& } 60.8 \text { for } \\
\text { infrasound. }\end{array}$ & $\begin{array}{l}\text { Self-reported } \\
\text { questionnaire } \\
\text { assessing } \\
\text { annoyance levels \& } \\
\text { residential } \\
\text { satisfaction. }\end{array}$ & $\begin{array}{l}\text { General opinion on wind } \\
\text { turbines, opinions on } \\
\text { altered views, possible } \\
\text { relationship between } \\
\text { participant \& operator, } \\
\text { self-reported types of } \\
\text { noise. In additional } \\
\text { models: age, education, } \\
\text { number of visible wind } \\
\text { turbines and distance to } \\
\text { the closest turbine. }\end{array}$ & Unspecified & N.S. \\
\hline
\end{tabular}

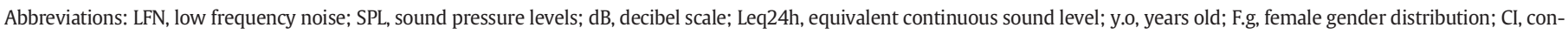
fidence interval; OR, odds ratio; N.S., no statistical significance.

a $\mathrm{O}=$ objective exposure assessment; $\mathrm{S}=$ self-reported exposure assessment. 
Table 4

Prevalence of high self-reported annoyance attributed to LFN, based on data from observational studies.

\begin{tabular}{llrlc}
\hline Study & Definition of high annoyance & $\begin{array}{l}\text { No. of people } \\
\text { annoyed }\end{array}$ & $\begin{array}{l}\text { No. of } \\
\text { participants }\end{array}$ & $\begin{array}{l}\text { Prevalence\% of annoyance } \\
(95 \% \mathrm{CI})\end{array}$ \\
\hline Persson Waye and Rylander (2001) & Being very annoyed to LFN from heat pump/ventilation installations & 6 & 279 & $2.2(1.0-4.7)$ \\
Fidell et al. (2002) & Being highly annoyed to LFN due to rattle and vibration produced by aircrafts & 128 & 495 & $25.9(22.0-29.9)$ \\
Persson Waye et al. (2003) & Being very or extremely annoyed by noise from fans/compressors & 14 & 41 & $34.1(21.4-49.7)$ \\
Magari et al. (2014) & Being very annoyed by LFN from wind turbines & 2 & 62 & $3.2(0.8-12.0)$ \\
Combined prevalence & & 150 & 877 & $10.5(3.0-30.9)$ \\
\hline
\end{tabular}

Abbreviations: Cl, confidence interval. 